\title{
THE ANALYSIS OF DRIVE SYSTEMS IN UNMANNED UNDERWATER VEHICLES TOWARDS IDENTIFYING THE METHOD OF DRIVE TRANSMISSION
}

\section{Bartłomiej Jakus, Adam Olejnik}

Polish Naval Academy, Department of Underwater Works Technology in Gdynia, Poland

\section{ABSTRACT}

This is the first part of the material concerned with the analysis of drive systems in remotely controlled unmanned underwater vehicles. The paper discusses the problem of classification of UUVs, mainly remotely controlled, with an indication of four different approaches to this issue. Moreover, the article discusses the nomenclature used in relation to various components of the discussed drive systems and thrusters, as well as indicates the functionality of such systems along with the advantages and disadvantages of the analysed design solutions. The method of analysis of drive systems, its methodology and the results will be the subject of a subsequent publication of the authors.

Keywords: marine engineering, underwater vehicles, underwater works technology.

ARTICLE INFO

PolHypRes 2017 Vol. 60 Issue 3 pp. 7 - 16

ISSN: $1734-7009$ elSSN: 2084-0535

Original article

DOI: $10.1515 /$ phr-2017-0010

Pages: 10, figures: 2 , tables: 0

Submission date: $13.08 .2017 \mathrm{r}$.

page www of the periodical: www.phr.net.pl

Acceptance for print: 29.09 .2017 r

Publisher

Polish Hyperbaric Medicine and Technology Society

Project implemented as part of the Regional Operational Programme of KujawskoPomorskie Voivodship for the years 2014-2020 INDUSTRIAL RESEARCH AND DEVELOPMENT WORKS TOWARDS THE DEVELOPMENT AND CONSTRUCTION OF AN INNOVATIVE HYBRID SUBMERSILE DEVICE IMPROVING SAFETY AND EFFICIENCY OF DIVING WORKS Project RPPM01.01.01-22-0055/16-00. Code name "ŚWIETLIK" Beneficiary: PBP "Forkos" Sp. $z 0.0$ 


\section{INTRODUCTION}

Unmanned underwater vehicles have been used for years in the exploration of bodies of water. The scope of their use for the implementation of such undertakings is widely described in literature $[1,2,3,4,6,9,14,15,17]$. In general, their purpose is to limit direct human involvement while performing tasks in an unfavourable environment, and to increase the efficiency of underwater works and underwater environmental research [5.12]. The variety of uses for unmanned underwater vehicles has resulted in a great many variations of design, these differing in size, shape, configuration of drive systems, thruster construction, power or control, and above all the onboard equipment encompassing a variety of auxiliary and peripheral mechanisms. Basic information on the construction of such devices has also been widely covered in literature $[4,5,11,12,14]$.

One of the trends in structural changes which have been introduced in vehicles in the last dozen or so years is the evolution of solutions connected with drive transmission from the motor to the thruster located in the vehicle's propulsors. The traditional solution involves transferring the torque of the electric motor to the propeller directly attached to the motor shaft, with magnetic coupling being used for this purpose in newer constructions [19]. The primary purpose of this solution is to increase the protection of the electric motor against the effects of flooding. The use of a magnetic coupling causes a complete separation of water-sensitive parts of the thruster, thereby increasing passive protection of the structure from the effects of submersion during deep-sea missions.

The purpose of this analysis is to identify the methods used to remotely control deep-sea vehicles with regard to propulsion transfer from the motors to the thrusters. Thus, in general this issue is related to their classification. Therefore, first and foremost, it is important to consider the general problem of classification of such devices.

\section{THE PROBLEM OF CLASSIFICATION OF UNMANNED UNDERWATER VEHICLES}

It is still problematic to compare particular constructions of unmanned underwater vehicles by their systematic assignment to specific groups, even for the professionals in the field. This is due to the wide range of solutions available and divergent approaches to the classification criteria. In general, the classification of a particular construction assumes an assignment of a given solution to a specific group of devices with similar technical characteristics or functionalities. It is also possible to introduce a division with regard to the applied method of control, i.e. the level of autonomy. In this case, we distinguish six classification levels from fully humanoperated devices during deep-sea missions (level 1) to fully autonomous devices, understood as vehicles capable of self-executing programmed operations without operator (human) intervention in different environmental conditions during the implementation of an entire task (level 6 autonomy) [16].

It should be noted that devices of the sixth autonomy level have not really been built yet. Vehicles currently used as autonomous are in fact seminautical constructions, i.e. such that are not capable of completing an entire deep-sea mission without the help and intervention of man - only part of the task is performed on their own. However, it does not change the fact that UUVs (unmanned underwater vehicles) are customarily divided into remotely operated vehicles (ROVs) and autonomous underwater vehicles (AUVs). Also, certain approaches support a general classification of UUVs as tethered and non-tethered vehicles. In general, a key differentiator is the use of an umbilical cable - if it is present the vehicle belongs to a tethered group, if not non-tethered. The issues related to the classification of AUV types were the subject of other publications $[13,14]$. In the case of devices that autonomously reach the task site and then switch to the remote operation mode during the performance of the main part of the mission, it is common to refer to these as hybrid or semiautonomous vehicles [18].

When it comes to ROVs, there are at least four approaches regarding their taxonomy. The first assumes that these devices should not be classified [11]. This logic assumes that each classification is related to the assignment of a given structure to a specific group of devices with similar characteristics. It is of course possible that a new generation of device is launched at any time, perhaps a vehicle with an innovative functionality which doesn't fit in the existing classification system, this vehicle maybe establishing a link between the differentiators of particular classification groups. Therefore, this is a fundamental disadvantage of the classification system and according to this school of thought.

ROV classification should be entirely abandoned.

The second approach assumes that such a situation is the greatest strength of the classification system $[4,5]$. At the time when a new solution appears which does not fit within the adopted classification, a new class of devices is created, thus enhancing the ROV taxonomy, which is based on the specification of the tasks performed and functionalities of particular devices.

The third approach suggests that the most relevant taxonomy of ROV vehicles is the one connected with the time of their development. As a result, the classification within this school of thought is based on a single criterion: vehicle weight $[7,8]$. It differentiates vehicles with a mass of up to $10 \mathrm{~kg}$ (microROV), between $10 \mathrm{~kg}$ and $50 \mathrm{~kg}$ (miniROV), $50 \mathrm{~kg}$ and $150 \mathrm{~kg}$ (compactROV) and over $150 \mathrm{~kg}$ (workROV). It should be noted that this approach to the taxonomy of ROV vehicles in Poland is reflected in the effective normative document. Standard N0-07-A118: 2015 Diving for military purposes. Terminology and classification distinguishes the following ROV classes [10]:

- mini ROV (weight up to $10 \mathrm{~kg}$ ),

- small ROV (weight between $10 \mathrm{~kg}$ and $50 \mathrm{~kg}$ ),

- average ROV (weight between $50 \mathrm{~kg}$ and 150 $\mathrm{kg}$ ),

- large ROV (weight over $150 \mathrm{~kg}$ ).

According to some researchers the above method of ROV classification is ambiguous as no strict limits have been determined [14], which may be a little surprising, since the weight assigned to particular classes is explicitly defined.

The fourth approach to the classification of this type of devices can definitely be referred to as an open approach. It allows for quite a substantial flexibility in classifying these devices in terms of their objectives and potential interests of the classifier. The said approach to 
ROV taxonomy is revealed by various types of organisations or vehicle manufacturers.

In the case of manufacturers the classification mainly consists in the proper sorting of the products they offer. On their websites one can find classification of vehicles according to ambiguous criteria, where both the mass of the vehicle and the power of its thrusters are applied simultaneously.

For example, such a classification includes [20a]:

- micro vehicles - up to $3 \mathrm{~kg}$,

- mini vehicles - about $15 \mathrm{~kg}$,

- general vehicles - with thruster power of less than $4[\mathrm{~kW}]$,

- $\quad$ light-duty vehicles - with thruster power of less than $40[\mathrm{~kW}]$,

- heavy-duty vehicles - with power above 40 [kW] but not exceeding $160[\mathrm{~kW}]$

- dredging vehicles - with power above over 160 $[\mathrm{kW}]$.

An equally ambiguous classification of vehicles is that accepted by the International Marine Contractors Association (IMCA), where the division depends on the functionality of the device, but also on the stage of its development.

This ROV taxonomy details the following five vehicle classes [21]:

- class I - observation vehicles,

- class II - observation vehicles with a charging option,

- class III - work vehicles,

- class IV - towed and bottom vehicles,

- class V - prototype vehicles.

As can be seen from the examples given above, the problem of classifying ROVs remains unresolved. This is most probably due to the considerable dynamics in the development of these devices and the fact that it is a highly interdisciplinary area today. Many professionals in the field of automation, computer science, robotics, mechatronics, and machine constructors and operators, who start their adventure with the technology of unmanned underwater vehicles, are trying to sort out this issue on their own. On the other hand, what is particularly evident in Poland, there are not many specialists dealing with their direct use and design. Due to the smaller size of the environment they do not have the opportunity to establish explicit taxonomic criteria. In short, in the face of the enormous fuzz, their voice is unnoticeable or marginal.

A tremendous role is also played by the media, which have popularised the word "drone", mainly as a synonym of an advancement in underwater technology, while signifying an opposite concept with regard to the adopted nomenclature for this type of devices.

The following part of this material utilises the ROV classification pursuant to the approach presented in standard industry terminology [10]. Nonetheless, it should be noted that the additionally applied division into devices with thrusters and direct drive on the propeller and magnetic coupling was used solely for the purpose of analysis of drive systems.
THE TRANSMISSION SYSTEM IN ROV THRUSTERS

In this material the following interpretations of terms related to the drive systems of ROVs have been adopted:

- VEHICLE'S DRIVE SYSTEM is a system of properly configured thrusters (set up, fixed) in a vehicle along with power supply and controlling devices.

- THRUSTER is a device that produces thrust.

With regard to the position of the thruster in the vehicle we distinguish the following thruster types:

- horizontal,

- vertical,

- vectored.

We distinguish the following thruster components:

- drive motor (electric, hydraulic),

- transmission system (drive shafts, mechanical coupling or magnetic coupling),

- thrust-generating device (propeller, nozzle screw, rotor in the water jet, jet drivers).

Whereas with regard to the construction we identify the following thruster types:

- axial (motor, transmission system and thrustgenerating device connected with one another and arranged along one axis),

- duct - rim thruster or brushless thruster, where the rotor and the rotating duct constitute a pair of electromagnetic actuators. The rotor is equipped with permanent magnets whereas the duct contains an electrically powered stator.

Fig. 1 shows examples of thrusters found in underwater vehicles. 


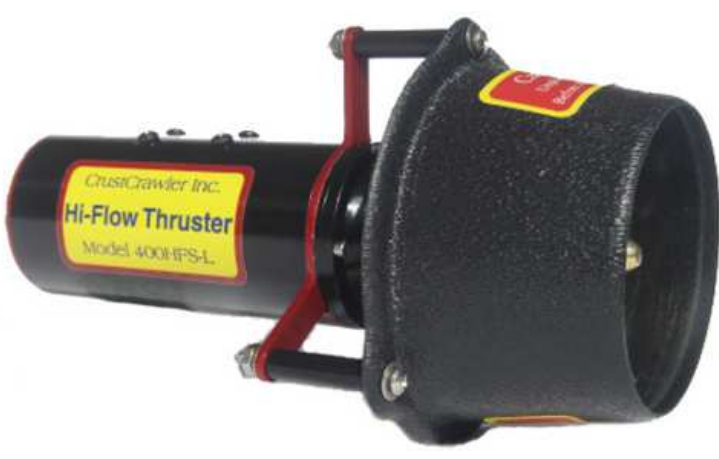

A

Fig. 1. Examples of thrusters found in ROVs

a) axial thruster b) duct-rim thruster [20b; 20c]

The purpose of the drive system of an underwater vehicle is to ensure adequate travel speeds in various directions, the ability to maintain the predetermined direction of navigation, the ability to maintain a predetermined depth or set distance from the bottom. The analysis of the drive systems of underwater vehicles shown in [12] reveals a large variety of configurations of thrusters depending on the size, type, purpose and working depth of the vehicle. This study also shows the construction of a typical thruster with an electric motor, however the drive transmission system between the electric motor and the propeller was not analysed. There are two technical solutions for

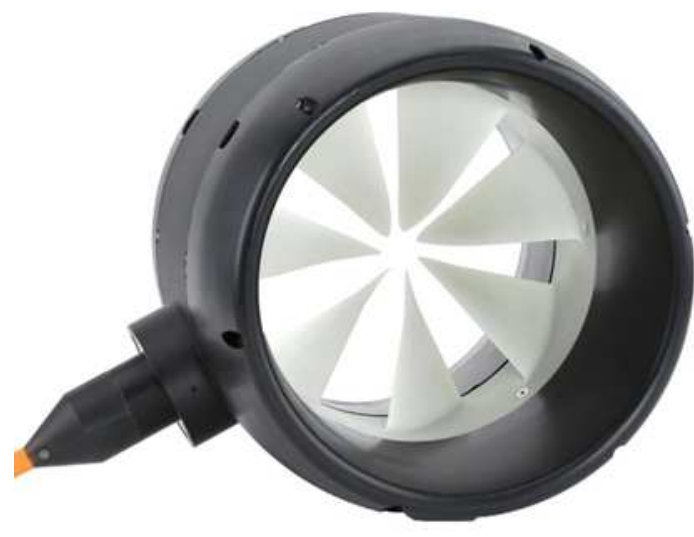

B

transferring the torque from an electric motor placed in a sealed pressure housing to a propeller located under water:

- traditional, with propeller situated directly on the motor shaft with proper rotary shaft seal at the exit from the motor housing (Fig. 1),

- by means of a magnetic coupling with a separation baffle which connects the motor shaft with propeller shaft without the need of a rotary seal in the motor housing (Fig. 2).

The diagrams below depict the discussed design solutions.

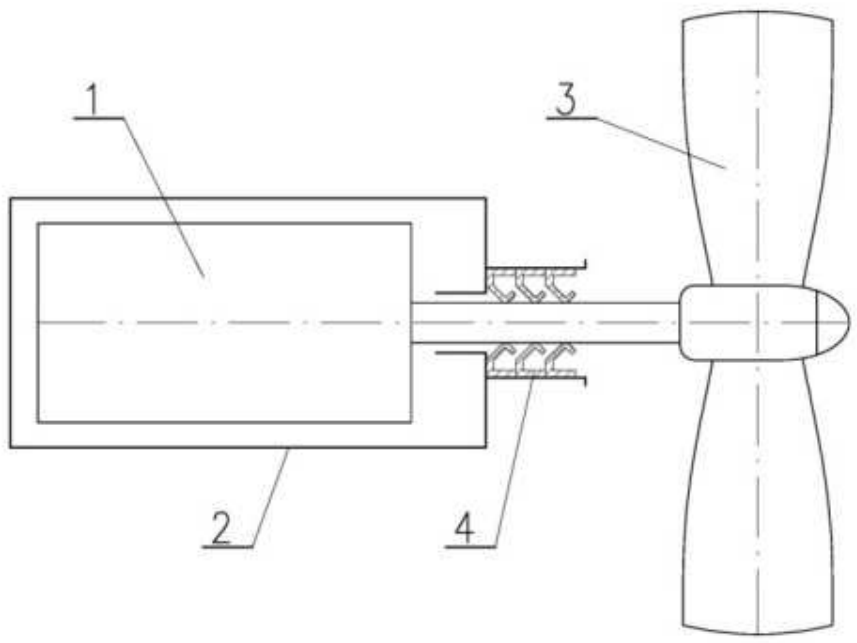

Fig. 1 The construction of an axial thruster with direct drive on the propeller.

1 - electric motor, 2 - waterproof housing of the electric motor, 3 - propeller, 4 - rotary seal of the motor shaft. 


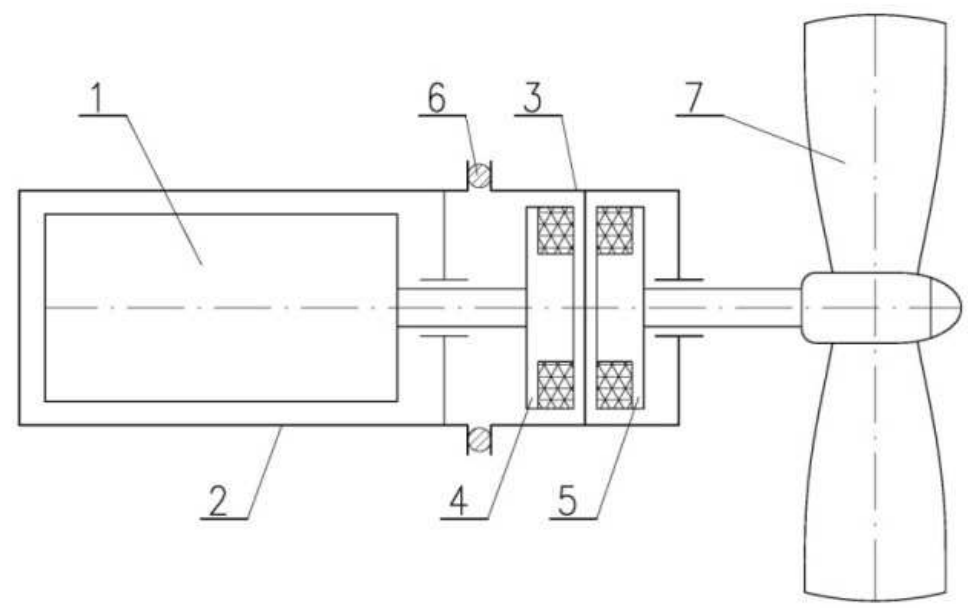

Fig. 2 The construction of an axial thruster with propeller drive by magnetic coupling.

1 - electric motor, 2 - waterproof housing of the electric motor, 3 - housing of the magnetic coupling, 4 - magnetised disk - active, 5 - magnetised disk passive, 6 - static seal, 7 - propeller.

Both of the above design solutions have their advantages and disadvantages. The characteristics of a particular technical solution are determined by the vehicle's working depth, thruster power and rotation, the size of the propeller and of the vehicle itself. Initial comparisons of both technical solutions allow for the specification of their main benefits and drawbacks.

In the case of a thruster with the direct drive on the propeller, the advantages include:

- transfer of the entire torque from the motor to the propeller,

- simple construction and a smaller length of the thruster.

Whereas among its disadvantages we may list:

- complicated construction of the motor shaft seal or the use of a pressure compensation system in motor housing,

- risk of flooding of the motor housing due to shaft seal damage during operation.
The following advantages are observed in the thruster using magnetic couplings to drive the propeller:

- static seal of the motor housing and low risk of flooding of the motor housing during operation.

Among the disadvantages of such a design solution we may distinguish:

- possibility of an occurrence of a slip during motor torque transfer onto the propeller by the magnetic coupling,

- complex construction and a greater length of the thruster.

The available literature lacks a comparative analysis concerned with the efficiency of both technical solutions of drive transmission. Due to the above reasons measures have been taken by the Department of Underwater Works Technology of the Naval Academy in Gdynia to evaluate particular vehicle constructions. The method of analysis, its methodology and results will be the subject of a subsequent publication of the authors.

\section{REFERENCES}

1. Burke S., Olejnik A.: Freedom of the Seas; Ed. STBB, Great Britain 2010, ISBN 978-0-9564790-0-6;

2. Christ R.D.; Wernli R.L.: The ROV manual; Ed. Elsevier 2007r., ISBN 978-0-7506-8148-3;

3. Grabiec D., Olejnik A.: Search and identification of underwater objects; chapter in: Collective work supervised by St. Poleszak: Wraki Bałtyku, Publ. KNOW Gdynia 2005, ISBN 83-920563-1-0, pp. 81-105;

4. Graczyk T.: Unmanned remotely controlled underwater vehicles - constructions and applications; Instytut Okrętowy Politechniki Szczecińskiej, Szczecin $1991 \mathrm{r}$ :

5. Graczyk T.: Design issues on the example of unmanned underwater vehicles; Politechnika Poznańska, Poznań 2008 r., Rozprawy Nr 421 , ISSN 0551-6528;

6. Olejnik A., Grządziel A., Szymaniuk R.: Research of identification and the inspection of the wreck "Graf Zeppelin"; Polish Hyperbaric Research nr 4(21) 2007 r., pp. 17-30, ISSN 1734-7009;

7. Olejnik A.: The development of the technique of underwater remotely operated vehicles; Polish Hyperbaric Research No. 3 (28)2009, pp. 7-21, ISSN 1734-7009;

8. Olejnik A.: The present status of the technique of underwater remotely operated vehicles; Polish Hyperbaric Research No. 3 (28)2009, pp. 2346, ISSN 1734-7009;

9. Olejnik A.: Visual indetification of underwater objects using a ROV type vehicle: Graff Zeppelin wreck investigation; Polish Maritime Research no. 1(55)2007, Vol. 1, pp. 72-79, ISSN 1233-2585;

10. Collective work: NO-07-A118:2015 Diving for military purposes. Terminology and classification;

11. Rowiński L.: The methodology of designing submersible devices at the concept stage with the use of computer techniques, Zeszyty Naukowe Politechniki Gdańskiej - Budownictwo Okrętowe Nr 59, Gdańsk 1993, ISSN 0373-869X;

12. Talaśka Zb., Olejnik A.: The analysis of the power transmission system of the remote underwater vehicles; Logistyka 2014, no. 4, pp. 13261336, ISSN 1231-5478;

13. Talaśka Zb., Olejnik A.: Autonomous underwater vehicles; Logistyka 2014 no. 4 pp. 1337 - 1351; ISSN 1231-5478;

14. Tariov A., Kruszko S.: Unmanned underwater vehicles, current state, business potential, perspectives for development; Elektronika: Konstrukcje, technologie, zastosowania; Vol. 52, no. 10; 2011, pp. 148-156; ISSN 0033-2089;

15. Wiliński A., Wróbel R.: Miniature remotely controlled underwater vehicles; Instytut Okrętowy Politechniki Szczecińskiej, Szczecin 1990,

16. Collective work: The concept of application of unmanned autonomous system in military forces; Centrum Doktryn i Analiz Sił Zbrojnych Bydgoszcz 2016: 
17. Olejnik A., Siermontowski P.: Will the underwater robot ever replace the diver? A rather poor progress or a great success?; Polish Hyperbaric Research No. 1, Vol. 54 2016, pp. 7-18, ISSN 1734-7009, DOI: 10.1515/phr-2016-0001;

18. Olejnik A.: Trends in the development of unmanned marine technology; Polish Hyperbaric Research No. 2, Vol. 55 2016, pp. 7-28, ISSN 1734 7009, DOI: 10.1515/phr-2016-0008;

19. Olejnik A., Chrabąszcz P.: Studies on the drive system of a prototypical remotely controlled underwater vehicle; Polish Hyperbaric Research No. 3(36) 2011 pp. 7 - 34; ISSN 1734-7009;

20. Internet sources:

21. https://en.wikipedia.org/wiki/Remotely_operated_underwater_vehicle\#Classification - accessed on 07.2017

22. http://www.crustcrawler.com/products/urov2/ - accessed on 07.2017

23. http://en.wikipedia.org/wiki/Underwater_thruster - accessed on 07.2017

24. Collective work: Guidance on competence assurance and assessment remote systems \& ROV division; IMCA C 005, Rev. 3; Great Britain 2016,

25. Collective work: Remotely Operated Vehicles of the World 2010/2011 $9^{\text {th }}$ edition; Publ. Clarcson Research Services Ltd. Londyn ISBN 978-1907060-14-4.

mgr inż. Bartłomiej Jakus

Zakład Technologii Prac Podwodnych

Akademia Marynarki Wojennej

81-127 Gdynia, ul. Śmidowicza 69

tel. 2612627 46; e-mail: b.jakus@amw.gdynia.pl 